\title{
Avaliação da influência da tipologia do minério em testes de sticking
}

\author{
Jean Philippe Santos Gherardi de Alencar ${ }^{1 *}$ (1) \\ Gabriel Silva do Carmo ${ }^{2}$ \\ Natállia Luiza Antunes Silva ${ }^{2}$ \\ Nathália Duarte Bastos ${ }^{2}$ \\ Pedro Silva Figueiredo ${ }^{2}$
}

\section{Resumo}

A cadeia produtiva da mineração de minério de ferro é extensa e flexível, inicia-se na lavra e tem como fim o momento de estocagem em pátios e expedições através de navios, trens ou caminhões. Independente da rota, um ponto chave comum é que o minério precisa ter uma boa escoabilidade ao longo do processo. Dependendo do nível de umidade, características intrínsecas do minério, circunstâncias de operação e dimensionamento dos equipamentos esse comportamento de escoabilidade se altera e traz consequências importantes para a eficiência técnica e econômica do empreendimento. Testes de bancada são relevantes nesse contexto, uma vez que contribuem para um melhor entendimento e previsibilidade de desempenho. No estudo em questão dois minérios de características diferentes: um de hematita granular e lamelar compacto e outro de hematita microcristalina porosa; foram submetidos a um teste experimental de Sticking em níveis de umidade distintos. Os resultados mostraram que: quanto maior a umidade, maior o grau de agarramento do material; para uma mesma umidade, o minério de hematita microcristalina apresenta maior tendência ao agarramento; o teste de bancada correspondeu e teve boa sensibilidade para avaliar os diferentes cenários.

Palavras-chave: Minério de ferro; Escoabilidade; Manuseio; Umidade.

\section{Evaluation of iron ore typology in sticking tests}

\begin{abstract}
The production chain of iron ore mining is extensive and flexible, it starts with mining and ends with storage in yards and expeditions by vessels, trains or trucks. Regardless of the route, a common key point is that the ore must have good flowability throughout the process. Depending on the level of moisture, iron ore intrinsic characteristics, operational aspects and dimensioning of the equipment, this flow behavior changes and leads to important consequences for the technical and economic efficiency of the project. Bench tests are relevant in this context, since they contribute to a better understanding and predictability of performance. In this study, two ores with different characteristics: one of compact granular and lamellar hematite and the other of porous microcrystalline hematite; were subjected to an experimental Sticking test at different moisture levels. The results showed that: the higher the moisture, the greater the sticking index of the material; at the same moisture level, the microcrystalline hematite ore is more likely to stick; the bench test corresponded and had good sensitivity to assess the different scenarios.
\end{abstract}

Keywords: Iron ore; Flowability; Handling; Moisture.

\section{Introdução}

\subsection{Contexto do problema}

A mineração é uma atividade que ao longo dos anos vem se mostrando de suma importância para o desenvolvimento tanto no aspecto de gerar a matéria-prima utilizada em larga escala em diversos setores da sociedade, como em função de empregar diversas pessoas na região, impulsionando assim o desenvolvimento econômico da mesma [1].

As reservas mundiais de minério de ferro são da ordem de 170 bilhões de toneladas. As reservas brasileiras

${ }^{1}$ Centro de Tecnologia de Ferrosos, Vale S.A., Nova Lima, MG, Brasil.

${ }^{2}$ Engenharia Química, Centro Universitário de Belo Horizonte-UniBH, Belo Horizonte, MG, Brasil.

*Autor correspondente: jeanpga@gmail.com

2176-1523 (C) 2021. Alencar et al. Publicado pela ABM. Este é um artigo publicado em acesso aberto (Open Access) sob a licença Creative Commons Attribution, que permite uso, distribuição e reprodução em qualquer meio, sem restrições desde que o trabalho original seja corretamente citado. 
representam $16,8 \%$ das reservas mundiais. No último ano (2019) a produção de minério de ferro foi de 410 milhões de toneladas [2]. Em termos de faturamento, estima-se que o setor mineral tenha atingido o montante de R \$ 153,4 bilhões, valor 39,2\% maior que o do ano anterior.

A relevância da indústria da mineração para o Brasil se deve não apenas pelos ganhos diretos, mas também pelos ganhos indiretos, uma vez que existem vários stakeholders envolvidos na cadeia. O sistema de produção do minério de ferro é caracterizado por um ciclo produtivo longo e contínuo, iniciado na mina, seguido pelo beneficiamento, transporte, estocagem, embarque e distribuição, e em grande maioria realizada através do sistema aquaviário. Em várias etapas do beneficiamento do minério de ferro é necessário utilização de água desde a etapa de pesquisa mineral seguida pelas etapas de lavra, tratamento do minério até a metalurgia extrativa [3]. Essa água, por vezes, pode gerar materiais extremamente úmidos, pastosos ou até mesmo água livre e isso ocasiona diferentes tipos de problema, como quebra de equipamentos, entupimentos, sobrecargas, desmoronamentos, soterramentos, reduções nas taxas de produção e provocar sérios riscos de acidentes, impactos ambientais além de navios com umidade TML (transport moisture limit).

Nesse contexto, o presente trabalho visou a estudar o impacto hidrodinâmico de duas diferentes tipologias de minério do ponto de vista de um teste de sticking (agarramento) de bancada.

\subsection{Referencial teórico}

\subsubsection{Uso da água na mineração}

A utilização e consumo de água nas atividades de mineração acontecem desde a implantação até o fechamento do empreendimento, principalmente, quando se utiliza o processo de separação a úmido [4]. Na lista abaixo enumeram-se alguns momentos onde a questão da água é pertinente nas etapas do processo:

- Mina: rebaixamento do lençol freático, tempo de exposição de minério desmontado, característica do minério, distribuição granulométrica e pluviometria;

- Usina: umidade do ROM e produtos, condições de desaguamento, alternativas de rotas;

- Pátio: drenagem dos pátios, tempo de residência, recuperação da pilha, efeito lava, pluviometria, umidade;

- Expedição: Desobstrução de silos, velocidade de carregamento, procedimento em casos de chuvas, cobertura de correias, umidade;

- Ferrovia: engenharia dos vagões, procedimentos de desentupimento, revestimento interno;

- Virador de vagões: condições dos viradores, automação, vibração, uso de substâncias químicas;
- Pátio: Não funcionamento de raspadores de correia, efeito de água livre, características de sticking nas correias e chutes, design de chutes;

- Embarque: TML, procedimento de embarque.

\subsubsection{Permeabilidade}

Permeabilidade está relacionada à capacidade de uma determinada amostra permitir a passagem de fluido sem a alteração de sua estrutura. Materiais permeáveis são aqueles que permitem a passagem de uma quantidade mensurável de fluido num período. Por outro lado, aqueles que permitem taxas de passagem desprezíveis são tidos como impermeáveis [5]

A granulometria das partículas, grau de compactação, forma dos grãos e composição mineralógica pode influenciar na permeabilidade. Tendo em vista o exposto, a litologia do minério de ferro deve influenciar a velocidade da passagem de água pela amostra, e como consequência, a retenção de umidade [5].

A permeabilidade é influenciada pela temperatura, tendo em vista que afeta a viscosidade e, consequentemente, a taxa de fluxo do fluido, pois altera a tensão superficial do líquido. Ademais, a permeabilidade também pode ser modificada pelo gradiente hidráulico ou coeficiente de permeabilidade que se altera pela uniformidade, pela faixa granulométrica, pela estratificação, pela compactação sofrida, ou mesmo pela presença e a natureza das descontinuidades [6].

\subsubsection{Capilaridade}

Sistemas particulados de drenagem de fluidos, retenção de umidade e aglomeração sofrem grande influência devido às forças capilares [7]. Tendo em vista o exposto, a capilaridade é um fator de grande importância para o desaguamento de sistemas particulados.

Segundo Azevedo [8], a capilaridade é a força criada pelo contato de um líquido com a superfície sólida. Quando ocorre esse contato, duas forças de sentidos opostos são criadas, a adesão que é a atração entre as moléculas dos líquidos e as moléculas dos sólidos, e a coesão, a qual advém das atrações entre as moléculas dos líquidos entre si. Molhabilidade é um fenômeno no qual um líquido se deforma baseado nas resultantes das interações intermoleculares com uma superfície sólida, quando ambos são colocados juntos. O grau de molhabilidade é determinado por um equilíbrio as forças de coesão e adesão [9].

Quando as forças de coesão são superiores as forças de adesão, um menisco convexo é formado, quando isso ocorre, o líquido tende a não molhar o sólido, formando um ângulo de contato maior que $90^{\circ}$ (sólidos liofóbicos, sendo que - quando o líquido é a água — são ditos hidrofóbicos). De modo contrário, caso as forças de coesão sejam inferiores às de adesão, um menisco côncavo é formado e o ângulo formado será inferior a $90^{\circ}$ (sólidos liofílicos, sendo que — quando o líquido é a água — são 
ditos hidrofílicos) [8]. A hidrofobicidade das partículas ou grãos influencia diretamente nos fenômenos de depressão e ascensão capilar.

\subsubsection{Retenção específica}

Retenção é a capacidade do meio poroso de imobilizar a água. Essa causa é resultante das forças moleculares e corresponde a água da superfície topográfica. Assim, parte da água infiltrada fica indisponível ao fluxo. A Retenção Específica é o complemento do armazenamento dos aquíferos livres [10].

\subsubsection{Tipologias do minério de ferro}

O ferro, em sua forma pura, é um metal maleável, de cor acinzentada, muito reativo e que se enferruja facilmente. $\mathrm{Na}$ natureza o ferro não está em estado livre ou elementar, mas é encontrado fazendo parte da composição de diversos minerais, principalmente de óxidos [11].

A hematita, pertence ao grupo dos óxidos, possui massa específica de $5,26 \mathrm{~g} / \mathrm{cm}^{3}$, sua dureza varia $5,5-6,5$; é um mineral do sistema hexagonal, podendo apresentar-se na cor castanho-avermelha ou preta, sendo que possui brilho metálico. Pode ser encontrada em rochas ígneas, metamórficas, sedimentares, sendo muito abundante no Quadrilátero Ferrífero (Minas Gerais) e Serra dos Carajás (Pará) [12]. Esse mineral pode ocorrer sob diversos tipos morfológicos. Becker et al. [13] subdivide os tipos morfológicos da seguinte forma:

Hematita microcristalina

- típica de minérios não metamorfizados;

- primeiro óxido de ferro a se formar através da sedimentação química de íons em suspensão;

- seu metamorfismo, geralmente dá origem a magnetita e posteriormente se altera para hematita;

- apresenta cristais de aspecto granular, formando partículas porosas e contato irregulares entre os cristais.

Hematita especular

- típica de minérios com alto grau de metamorfismo;

- apresenta cristais compactos, pouco porosos, lateral retilíneos, com relação entre comprimento e largura maior que $5: 1$.

Hematita lamelar

- semelhante a hematita especular;

- seus cristais apresentam relação comprimento e largura menor que 5:1.

Hematita granular

- possui cristais de aspecto granular, equidimensionais e geralmente compactos (pouco porosos);

- nas partículas policristalinas apresentam contatos retilíneos e junções tríplices entre si.

Hematita sinuosa

- também chamada de hematita recristalizada;
- apresentam cristais compactos de aspecto granular, inequidimensionais e irregulares;

- nas partículas policristalinas apresentam contatos sinuosos e entrelaçados.

Hematita martítica

- formada pela oxidação da magnetita;

- apresenta microporosidade característica e podem ocorrer de forma totalmente irregular;

- nas partículas policristalinas apresentam contatos laterais e retilíneos quando o hábito da magnetita é preservado, ou irregulares, caso o hábito não seja preservado.

A goethita, pertence ao grupo dos óxidos, possui massa específica de $4,37 \mathrm{~g} / \mathrm{cm}^{3}$, sua dureza varia $5-5,5$, é um mineral do sistema cristalino ortorrômbico, podendo apresentar-se nas cores preto-amarronzado ou marrom-avermelhado, sendo que possui brilho metálico a submetálico [12]. Esse mineral pode ocorrer sob diversos tipos morfológicos. Becker et al. [13], subdivide os tipos morfológicos da goethita sendo:

Goethita compacta

- apresenta cor cinza azulada, podendo ocorrer reflexão interna nas cores laranja, vermelho ou amarelo;

- microestruturas variadas (maciço, botrioidal, alveolar, fibrosa - anfibolítica);

- pode conter quantidades variadas de água e outros componentes $\left(\mathrm{P}, \mathrm{Al}_{2} \mathrm{O}_{3}, \mathrm{SiO}_{2}\right)$;

- produto de intemperismo de outros minerais de ferro. Goethita terrosa

- apresenta cores variadas: marrom claro, amarelado, avermelhado, etc.;

- apresenta grau de hidratação elevado, consistência terrosa, granulometria muito fina;

- a quantidade de água varia e apresenta maiores teores de contaminantes.

A magnetita, pertence ao grupo dos óxidos, possui massa específica de $5,18 \mathrm{~g} / \mathrm{cm}^{3}$, dureza igual a 6 , é um mineral do sistema cúbico, podendo apresentar-se na cor preta, com possui brilho metálico [12]. Becker et al. [13] apresenta a magnetita conforme:

- ao microscópio ótico apresenta cor rósea a cinza-amarronzado e não apresenta reflexões internas;

- podem apresentar cristais compactos ou porosos, com aspecto granular, totalmente irregulares e alta resposta magnética;

- mineral comum e pode formar grandes corpos de minérios.

\subsubsection{Problemas gerados pela umidade}

O teor de água em minério contém relevância industrial e comercial, em que o estudo se revela essencial para entender e melhorar pontos relacionados à produção e transporte do mesmo. Em termos de comercialização, o preço do minério de ferro em relação ao frete, é calculado a partir do teor de ferro e umidade, na qual são realizados 
descontos conforme o teor de contaminante $\mathrm{SiO}_{2}$ e $\mathrm{Al}_{2} \mathrm{O}_{3}$, quando estão acima de um limite definido [14].

Não obstante, um dos grandes problemas da água superficial nos minérios é o sticking, palavra inglesa que significa colagem e aderência, que é quando o material tem a tendência de ficar em repouso sobre outro até certo ângulo sem interferir nas propriedades intrínsecas e intensivas, variando apenas o comportamento do material no ambiente em questão. Tal acontecimento gera uma série de problemas, a maioria deles ligados ao fato de o material não escoar e se manter preso em paredes. Exemplo como o descarregamento de vagões, silos e material agarrado em pontos de transferências como chutes de correias são típicos transtornos recorrentes no ambiente de mineração. A Figura 1 apresenta como o material colado nas paredes dos vagões atrapalha seu descarregamento. Encontrar métodos de realizar testes que avaliem a susceptibilidade de determinados minérios ao sticking é uma maneira muito útil de contribuir para o entendimento acadêmico do problema e propiciar às empresas melhores condições de terem previsibilidade em seus processos.

\section{Materiais e métodos}

\subsection{Materiais}

Os materiais utilizados nesse estudo visaram a representar duas tipologias diferentes de minério de ferro: uma de hematita porosa e outro de hematita compacta. Nas Tabelas 1, 2 e 3 é possível ver, respectivamente, os resultados de observação das fases cristalinas, morfologia e a distribuição granulométrica das amostras utilizadas nos testes.

A caracterização microestrutural fornece informações importantes acerca das fases presentes: hematita, goethita, magnetita, quartzo e suas respectivas morfologias e a porosidade textural. Notou-se qualitativamente que a amostra intitulada de Hematita Porosa realmente apresentava texturas mais porosas tanto na hematita presente quanto na goethita. O microscópio utilizado é do de luz refletida da marca Carl Zeiss modelo AxioImager Z2m, com analisador de imagens e software de tratamento de imagem.

A caracterização granulométrica foi feita a partir de um peneiramento a úmido utilizando-se um peneirador suspenso da CDC. O tempo de peneiramento foi mantido constante e igual há 20 minutos. O material era empolpado numa percentagem de sólidos na faixa de 40 a 50\%. No término do teste, as frações retidas nas peneiras foram removidas e filtradas utilizando-se papel filtro e bomba de vácuo. Após a filtragem as frações retidas foram secas em estufa com temperatura não superior a $120^{\circ} \mathrm{C}$ e finalmente, foram realizadas as pesagens de cada fração retida, para o cálculo da distribuição granulométrica. Constata-se que o material de Hematita Poroso é mais grosso, no geral, porém ele apresenta uma proporção de ultrafinos $(<0,045 \mathrm{~mm})$ superior ao material de Hematita Compacta.

\subsection{Métodos}

A quantidade de cada minério utilizada é de $500 \mathrm{~g}$, em peso seco. Os demais itens necessários para a realização dos testes de bancada foram: pulverizador de água; lona; espátula; béquer; placa de Teflon; bandeja de alumínio; trena; cronômetro e balança analítica.
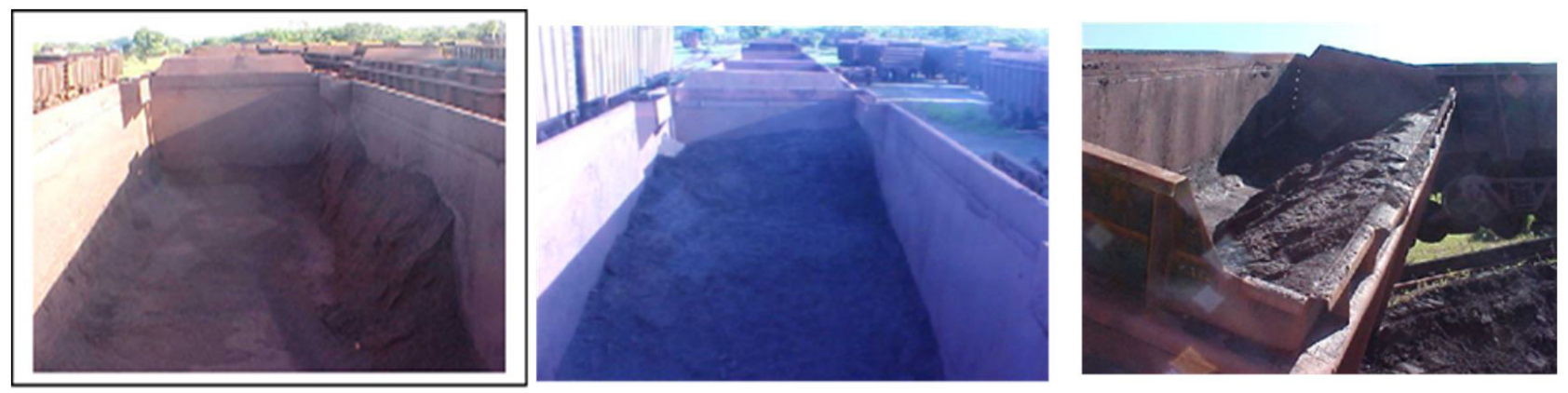

Figura 1. Foto de rechego nos vagões.

Tabela 1. Caracterização da mineralogia das amostras

\begin{tabular}{llcc}
\hline \multicolumn{1}{c}{ Fase Cristalina } & Unidade & Hematita Compacta & Hematita Porosa \\
\hline Hematita $\left(\mathrm{Fe}_{2} \mathrm{O}_{3}\right)$ & \% Massa & 82 & 74 \\
Goethita/Limonita $(\mathrm{FeO} . \mathrm{OH})$ & \% Massa & 9 & 19 \\
Magnetita $\left(\mathrm{Fe}_{3} \mathrm{O}_{4}\right)$ & \% Massa & 2 & 2 \\
Quartzo $\left(\mathrm{SiO}_{2}\right)$ & \% Massa & 7 & 4 \\
\hline
\end{tabular}


Na Figura 2 apresentam-se as etapas do teste de bancada que se resumem em: (1) homogeneizar o material de um determinado ponto experimental e posiciona-lo a uma altura de $60 \mathrm{~cm}$ acima da placa de Teflon; (2) deixar o material cair livremente sobre a placa de Teflon; (3) aguardar alguns segundos com a placa na horizontal; (4) posicionar

Tabela 2. Caracterização morfológica das amostras

\begin{tabular}{lccc}
\hline \multicolumn{1}{c}{ Fase Cristalina } & Unidade & $\begin{array}{c}\text { Hematita } \\
\text { Compacta }\end{array}$ & $\begin{array}{c}\text { Hematita } \\
\text { Porosa }\end{array}$ \\
\hline Microcristalina & \% Massa & - & 53 \\
Martita & \% Massa & 6 & 21 \\
Lobular & \% Massa & $<1$ & - \\
Granular & \% Massa & 29 & 2 \\
Lamelar & \% Massa & 52 & 2 \\
Magnetita & \% Massa & 2 & 2 \\
Goethita & \% Massa & 10 & 20 \\
\hline
\end{tabular}

Tabela 3. Caracterização granulométrica das amostras

\begin{tabular}{cccc}
\hline $\begin{array}{c}\text { Abertura da } \\
\text { Peneira }\end{array}$ & Unidade & $\begin{array}{c}\text { Hematita } \\
\text { Compacta }\end{array}$ & $\begin{array}{c}\text { Hematita } \\
\text { Porosa }\end{array}$ \\
\hline $1,0 \mathrm{~mm}$ & \% retida & 31,3 & 46,4 \\
$0,15 \mathrm{~mm}$ & \% retida & 55,6 & 71,2 \\
$0,045 \mathrm{~mm}$ & \% retida & 81,1 & 78,4 \\
\hline
\end{tabular}

a placa na posição vertical e aguardar 10 segundos; (5) após o tempo de espera medir o peso do conjunto placa de Teflon + minério agarrado e comparar com o peso da placa de Teflon inicial e seca.

\section{Resultados e discussão}

A fim de gerar uma comparação não apenas limitada ao contexto da tipologia mineral, foi gerado também níveis diferentes de umidade entre os dois materiais alvo do estudo. Esses níveis de umidade foram definidos em 5\%,10\% e 15\%. A Tabela 4 consolida todos os dados parciais necessários para a obtenção do valor final de Índice de Sticking, que é dado por ((Peso placa Teflon + Minério - Peso placa Teflon)/Peso amostra úmida) x 100\%. Em todos os testes a massa inicial de minério era $500 \mathrm{~g}$ e o peso da placa de Teflon seca e limpa era de aproximadamente $458 \mathrm{~g}$.

$\mathrm{Na}$ Figura 3 observa-se o gráfico dos resultados do índice de Sticking em função da umidade e separado em duas séries de dados, conforme respectiva tipologia. É interessante notar que, para uma mesma umidade, a Hematita Porosa sempre apresentou maior valor de Índice de Sticking que a Hematita Compacta. Além disso, foi notório que à medida que a umidade acrescia, o Índice de Sticking se elevava em proporções diretas. Numa curva linear de tendência, obteve-se coeficiente de determinação $\left(\mathrm{R}^{2}\right)$ de 0,90 para a série de dados de Hematita Porosa e de 0,79 para a séria de dados da Hematita Compacta.

Tabela 4. Dados para obtenção do Índice de Sticking

\begin{tabular}{lcccc}
\hline \multicolumn{1}{c}{ Minério } & Teste & Umidade (\%) & Peso Teflon + Minério (g) & Índice de Sticking (\%) \\
\hline Hematita Compacta & 1 & 5 & 458,28 & 0,04 \\
Hematita Compacta & 2 & 10 & 459,29 & 0,22 \\
Hematita Compacta & 3 & 15 & 478,63 & 3,57 \\
Hematita Porosa & 4 & 5 & 458,78 & 0,13 \\
Hematita Porosa & 5 & 10 & 464,92 & 1,24 \\
Hematita Porosa & 6 & 15 & 466,48 & 5,34 \\
\hline
\end{tabular}
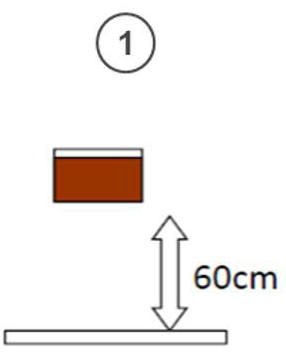
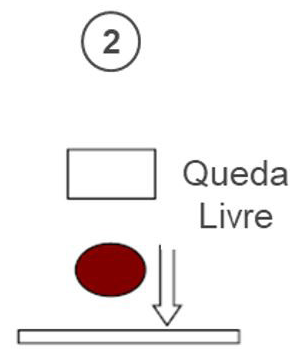
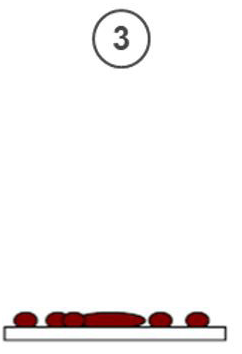

(4)

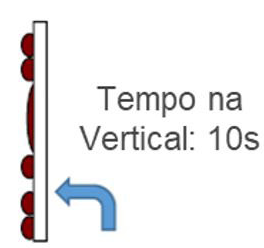

(5)

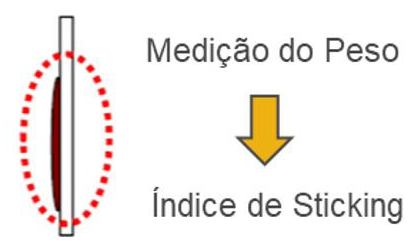

Figura 2. Procedimentos do Teste. 


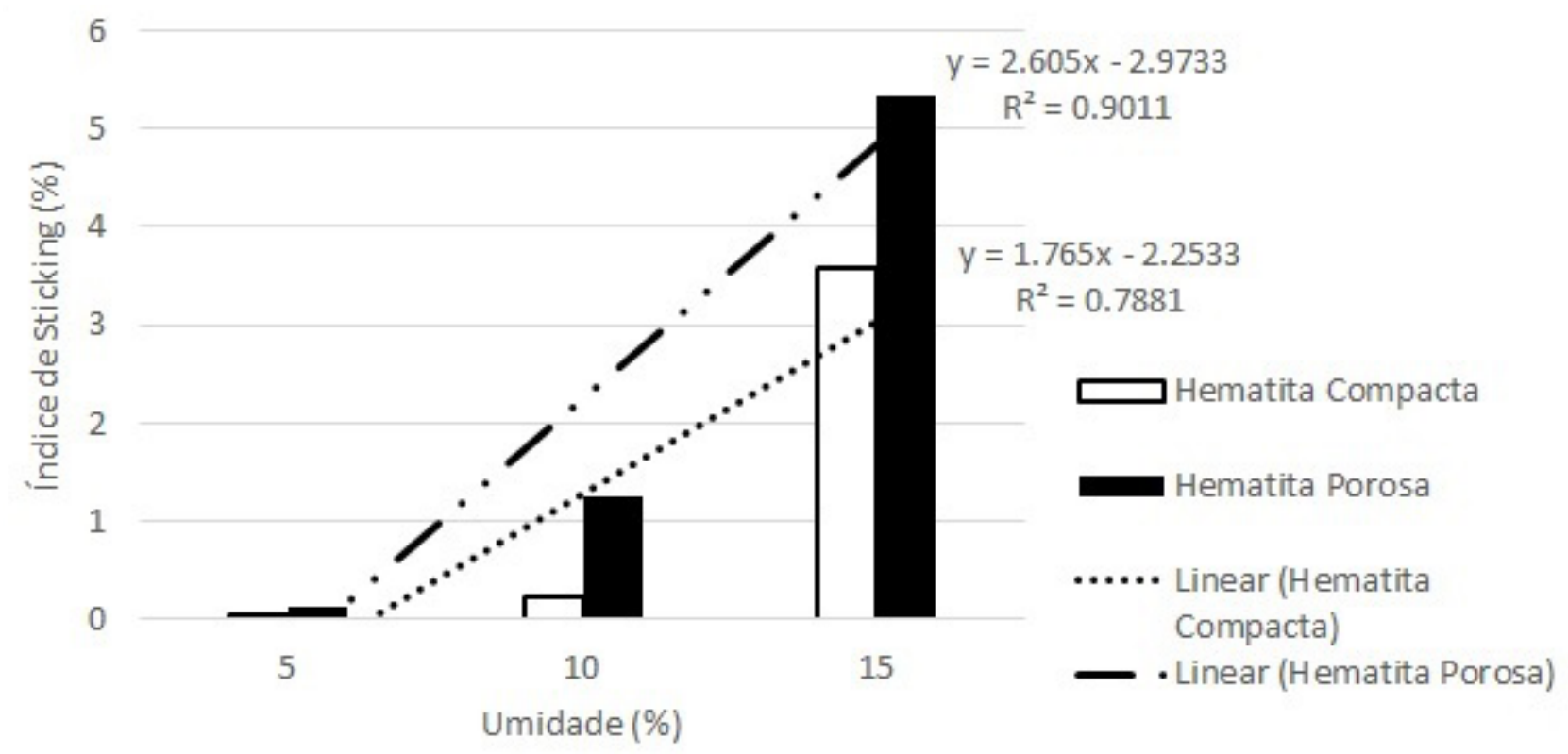

Figura 3. Gráfico de barras dos dados de Índice de Sticking.

\section{Conclusões}

A partir dos dados obtidos com este estudo pode-se afirmar que:

- O aumento da umidade implica no aumento do índice de Sticking independente da tipologia do minério, o que corrobora a literatura uma vez que quanto mais umidade até o ponto antes de formação de lama, espera-se que a tendência ao escoamento diminua;

- Para um mesmo nível de umidade o minério com estrutura de hematita porosa apresentou maior índice de Sticking e isso provavelmente se deve não apenas aos aspectos de morfologia, mas também pode estar associado ao fato de minério conter mais ultrafinos na sua distribuição granulométrica;

- A tentativa de se utilizar uma metodologia de bancada com uso de placas de Teflon para estimar quantitativamente o índice de Sticking se mostrou eficaz e tem capacidade de gerar informações relevantes para o trabalho de previsibilidade e ajustes de processo que mitiguem os potenciais riscos associados ao contexto de altas umidades na cadeia produtiva de minério de ferro.

\section{Referências}

1 Oliveira MC, Rodrigues EP, Arthur AC. Ardósia como matéria prima cerâmica. In: Anais do $44^{\circ}$ Congresso Brasileiro de Cerâmica; 2000; São Pedro. São Paulo: Associação Brasileira de Cerâmica; 2000

2 Agência Nacional de Mineração. Informe mineral. Brasília: ANM; 2018. p. 2-4.

3 Castro Neto LR. Modelagem e simulação da cadeia produtiva do minério de ferro [tese]. São Paulo: Universidade de São Paulo; 2006.

4 Ciminelli VST, Salum MJG, Rubio J, Peres AEC. Água e mineração. In: Rebouças AC, Braga B, Tundisi JG, editores. Águas doces no Brasil: capital ecológico, uso e conservação. 3. ed. São Paulo: Escrituras; 2006.

5 Quites NAS. Inflluência de diferentes tipos de minério de ferro na umidade do sinter feed [dissertação]. Ouro Preto: a Universidade Federal de Ouro Preto; 2018.

6 Bell FG. Fundamentals of engineering geology. Kent: Elsevier; 2016.

7 Schubert H, Freiberg B. Capillary forces-modeling and application in particulate technology. Powder Technology. 1984;37:105-116.

8 Azevedo JMCB. Absorção por capilaridade de soluções aquosas salinas em materiais porosos [dissertação]. Porto: Universidade do Porto; 2013.

9 Lévy E. Dicionário de física. São Paulo: Melhoramentos; 1993. 537 p. 
10 Wrege M. Termos hidrogeológicos básicos. São Paulo: Associação Brasileira de Águas Subterrâneas; 1997.

11 Luz AB, Sampaio JA, França SCA. Tratamento de minérios. Rio de Janeiro: CETEM; 2010.

12 Klein C, Dutrow B. Manual da ciência dos minerais. 23. ed. Porto Alegre: Bookman; 2012.

13 Becker M, Wightman EM, Evans CL. Process mineralogy. Vol. 1. Quennsland: Julius Kruttschnitt Mineral Research Centre; 2016.

14 Cunha CCRF. Determinação dos teores de água em amsotras de minério de ferro, manganês e de oxihridróxidos de ferro sintéticos [dissertação]. Ouro Preto: Universidade Federal de Ouro Preto; 2016.

Recebido em: 16 Jun. 2020

Aceito em: 18 Ago. 2020 